\title{
Clasificación del uso de suelo y vegetación en áreas de pérdida de cobertura arbórea (2000-2016) en la cuenca del río Usumacinta
}

\author{
Classification of land use and vegetation in tree cover loss areas \\ (2000-2016) in the Usumacinta river watershed
}

\author{
Candelario Peralta-Carreta', J. Alberto Gallardo-Cruz, Jonathan V. Solórzano' y Matías Hernández-Gómez'
} ' Centro del Cambio Global y la Sustentabilidad, A.C.
Villahermosa, Tabasco, México.

\author{
2 Universidad Iberoamericana. Centro Transdisciplinar \\ Universitario para la Sustentabilidad. Ciudad de \\ México, México.
}

\section{RESUMEN}

A escala mundial, la mayor parte de los estudios sobre la pérdida de cobertura arbórea se enfocan en cuantificarla por medio de técnicas de percepción remota. Dichas estimaciones frecuentemente omiten la información del tipo de uso de suelo y vegetación, por lo que limitan el entendimiento de las pérdidas ocurridas para cada una de estas clases. Con el fin de conocer cuáles han sido las comunidades vegetales más afectadas por el proceso de pérdida de cobertura arbórea en el periodo 2000-2016 en la cuenca del Usumacinta en este estudio se analizaron de manera simultánea dos fuentes de información disponibles: la Serie II de Uso de suelo y vegetación del Instituto Nacional de Estadística y Geografía de México (Inegi, 2001) y la evaluación del cambio en la cobertura forestal a escala global (Hansen et al., 2013). Los resultados indican que de las 347317.68 ha de cobertura arbórea perdidas entre el 2000 y 2016 en la cuenca, $62 \%$ correspondió a tres categorías: la selva alta perennifolia (SAP, 26\%), uno de los tipos de vegetación más biodiversos del país; la vegetación secundaria de selva alta perennifolia (VSSAP, 19.1\%) y el pastizal cultivado inducido (PCI, 17.0\%), una clase fuertemente transformada por las actividades antrópicas. Las pérdidas de la SAP y de la VSSAP se concentraron principalmente en la porción media y media/alta de la cuenca, respectivamente, mientras que la del PCI en la parte baja. De manera opuesta, las clases de vegetación con menor pérdida de cobertura arbórea fueron también las menos representadas en superficie en la cuenca. Los resultados derivados de este trabajo servirán para identificar los sistemas más amenazados y orientar las acciones de conservación en la región.

PALABRAS CLAVE: pastizal cultivado o inducido; porción alta de la cuenca; porción baja de la cuenca; porción media de la cuenca; selva alta perennifolia; Serie II del Inegi; vegetación secundaria.

\section{ABSTRACT}

Worldwide, most tree cover loss studies are focused on quantifying it by means of remote sensing techniques. These studies frequently omit land use and vegetation classes, thus, the information of loss occurring for each of the land use vegetation types that exists in a region is limited. In order to identify which plant communities have been most affected by the tree cover loss process in the period 2000 - 2016 within the Usumacinta basin, in this study, two sources of information were analyzed simultaneously, namely: the series II of land use and vegetation of the National Institute of Statistics and Geography of Mexico (Inegi) and the results from the evaluation of change in tree cover at the global scale made by Hansen et al. (2013). The results indicate that of the 347317.68 ha of tree cover lost between 2000 and 2016 in the basin, $62 \%$ corresponds to three categories: the tropical rain forest (26\%), one of the most biodiverse vegetation types in the country, secondary vegetation derived from tropical rain forest (19.1\%) and the cultivated grassland (17\%), a class strongly affected by anthropogenic activities. Most of the rain forest loss was concentrated on the medium part of the basin, while most of the grassland loss was located in the lower region. Conversely, the vegetation classes with less tree cover loss were also the least represented on the surface in the basin. The results derived from this work will serve to identify the most threatened systems and guide conservation actions in the region.

KEYWORDS: cultivated grassland; high, medium and low portions of the basin; tropical rain forest; Series II Inegi; secondary vegetation. 


\section{INTRODUCCIÓN}

La pérdida de la cobertura arbórea de la vegetación tropical es uno de los eventos más catastróficos de la actualidad (Barnosky et al., 2012; Rosa, Smith, Wearn, Purves y Ewers, 2016). Entre las consecuencias de la pérdida del componente arbóreo de estos tipos de vegetación se encuentran: la pérdida de especies y diversidad genética (Dirzo, 2004; Giam, 2017; Lowe, Boshier, Ward, Bacles y Navarro, 2005), la disminución de los recursos forestales (Ortiz-Espejel y Toledo, 1998) y de servicios ecosistémicos (Naidoo et al., 2008; Steffen et al., 2004), así como las afectaciones en los sistemas hídricos y climáticos a escala mundial (Houghton, 1990; Laurance, 1999; Lawrence y Vandecar, 2015; O'Brien, 1995; Zhang, Henderson-Sellers y Mcguffie, 2001). En este sentido, la importancia de cuantificar e identificar los patrones espaciotemporales de la pérdida de cobertura arbórea es clave para entender este fenómeno y plantear medidas que permitan frenarlo (Funi y Paese, 2012; Murray, Grenyer, Wunder, Raes y Jones, 2015).

El uso de técnicas basadas en la percepción remota ha demostrado su utilidad para estimar el estado de los bosques y sus características a partir de sus propiedades reflectivas en determinadas longitudes del espectro electromagnético (Miller y Rogan, 2007; Song, Gray y Gao, 2011; Wang, Franklin, Guo y Cattet, 2010; Xie, Sha y Yu, 2008). Este tipo de estudios han sido una herramienta útil para delimitar y calcular la extensión de los diferentes tipos de vegetación, así como la extensión y localización de las áreas de pérdida de cobertura arbórea (Couturier, Núñez y Kolb, 2012; Food and Agriculture Organization [FAO], 2018a; Instituto Nacional de Estadística y Geografía [Inegi], 2013; Sexton et al., 2013).

En 2013 se publicó un análisis que utilizó imágenes Landsat (misiones 4-8) para estimar la pérdida anual de cobertura arbórea para el periodo comprendido entre los años 2000 y 2012 a escala global (Hansen et al., 2013). La estimación de la exactitud total con algunos puntos de verificación de la clasificación en zonas que sufrieron algún proceso de pérdida de cobertura arbórea o conservación fue de alrededor de 99\% (Hansen et al., 2013). Dicho estudio continúa actualizando sus resultados. Esta información, junto con otros estudios similares (Gibbs et al., 2010; Malhi, Gardner, Goldsmith, Silman y Zelazowski, 2012), han permitido hacer estimaciones del grado de la pérdida de cobertura arbórea a diferentes escalas de interés (continente, país, región, estado), identificar tendencias temporales (aumento o disminución de la pérdida de cobertura arbórea) y zonas de pérdida o ganancia importantes de cobertura arbórea.

A pesar de la enorme relevancia de la información publicada por Hansen et al. (2013), este estudio no permite identificar qué clase de uso de suelo o tipo de vegetación pasó por algún proceso de pérdida de cobertura arbórea en el periodo de análisis. Esta discriminación resulta de particular importancia para fines de conservación de la biodiversidad, ya que diferentes tipos de vegetación albergan diferentes especies y la superficie ocupada por los diferentes tipos de vegetación suele ser heterogénea (Inegi, 2013; Secretaría del Medio Ambiente y Recursos Naturales [Semarnat] y Comisión Nacional de Áreas Naturales Protegidas [Conanp], 2016). Además, resulta importante poder distinguir entre los diferentes estadios sucesionales de un mismo tipo de vegetación. Por ejemplo, una vegetación madura suele contener un mayor número de especies y mayor cantidad de carbono capturado que su equivalente sucesional temprano (Liu, Liu y Skidmore, 2017; Nelson, Kimes, Salas y Routhier, 2000; Quesada et al., 2009; Steininger, 2000; Turner, Wong, Chew y Ibrahim, 1997). Sin embargo, la vegetación secundaria suele capturar carbono más rápido que su equivalente maduro (Mukul, Herbohn y Firn, 2016; Poorter et al., 2016; Stas, 2014).

En este sentido, resulta de crucial importancia para el adecuado manejo y conservación de la vegetación tropical contar con información detallada que permita evaluar la pérdida de cobertura arbórea por cada clase de uso de suelo y vegetación presente en la región. A pesar de que en México existe la información de tipos de uso de suelo y vegetación (Inegi series I-VI), la cual permite hacer evaluaciones sobre la superficie perdida; no permite hacer 
cuantificaciones con tanto detalle como la información de Hansen et al. (2013) y tiene el problema de la homologación de las clases entre series.

\section{OBjetivos}

Este trabajo planteó como objetivo central conocer cuáles han sido las clases de uso de suelo y tipos de vegetación más afectadas por el proceso de pérdida de cobertura arbórea en el periodo 2000-2016 en la cuenca del Usumacinta a partir del análisis conjunto de dos fuentes de información disponibles: la Serie II de Uso de suelo y vegetación del Inegi y la Evaluación del cambio en la cobertura forestal a escala global de Hansen et al. (2013).

\section{MATERIALES Y MÉTODOS}

\section{Sitio de estudio}

La zona de estudio corresponde con la parte mexicana de la cuenca del río Usumacinta (CRU), la cual fue delimitada utilizando criterios topográficos, cartográficos y geomorfológicos (Fig. 1). Esta cuenca fue elegida debido a su importancia en términos de biodiversidad, captación de agua (Comisión Nacional del Agua [Conagua], 2014; Cotler-Ávalos, 2010), captura de carbono, entre otros (Carabias, de la Maza y Cadena, 2015). La totalidad de la cuenca ocupa 7743597 ha (incluyendo Guatemala y una pequeña porción en Belice); sin embargo, la parte mexicana corresponde a 3426919 ha distribuidas en los estados de Tabasco, Chiapas y Campeche. En la CRU se reconocen tres porciones que comparten características topográficas, geomorfológicas e hidrográficas. Estas porciones son: la zona de captación (cuenca alta), la zona de transporte y transferencia (cuenca media) y la zona de descarga (cuenca baja). La cuenca alta se ubica en México en las montañas de los Altos de Chiapas. La cuenca media ocupa gran parte de la región de la selva Lacandona, mientras que la baja abarca la extensa zona de humedales continentales del río San Pedro y las zonas de humedales de la planicie deltaica del Usumacinta (Fig. 1).
Dentro de la CRU existe una alta diversidad de tipos de vegetación. Entre los más importantes se incluyen: vegetación hidrófila (popal, tular, manglar), bosques templados (bosques de pino, encino, mesófilo de montaña) y tropicales (selva alta perennifolia, selva mediana subperennifolia) y varios tipos de sistemas antropizados (pastizales cultivados y agricultura). Es importante destacar que dentro de la CRU dos áreas de enorme importancia biológica están protegidas por alguna modalidad de la legislación mexicana: la Reserva de la Biosfera de Montes Azules y por otro lado el conjunto formado por la Reserva de la Biosfera Pantanos de Centla y el área de Protección de Flora y Fauna de Laguna de Términos (Instituto Nacional de Ecología [INE] y Secretaría de Medio Ambiente, Recursos Naturales y Pesca [Semarnap], 1994, 2000a, 2000b). Ambos sistemas proveen una variedad de servicios ecosistémicos que incluyen la protección de la línea de costa, sitios de anidamiento de aves y especies de importancia económica, captura de carbono y captación de agua (Carabias et al., 2015; INE y Semarnap, 1994, 2000a, 2000b; Lahmanm y Córdova, 1999).

\section{Información utilizada}

Se utilizaron dos fuentes para identificar los tipos de uso de suelo y vegetación con mayor pérdida de cobertura arbórea en el período 2000-2016: los tipos de uso de suelo y vegetación de la Serie II del Inegi (Inegi, 2001) y la información de pérdida de cobertura arbórea (Hansen et al., 2013).

\section{Información de tipos de vegetación}

La Serie II de los tipos de uso de suelo y vegetación, escala 1:250 000 (unidad mínima cartografiable $=100 \mathrm{ha}$ ), fue creada por el Instituto (Inegi, 2001) a partir de información recopilada mediante fotointerpretación y datos de campo. Esta serie se eligió debido a que las fuentes de información utilizadas para crearla corresponden temporalmente con el año inicial del estudio de la pérdida de cobertura arbórea (2000). Esta fuente representa la mejor información de su 


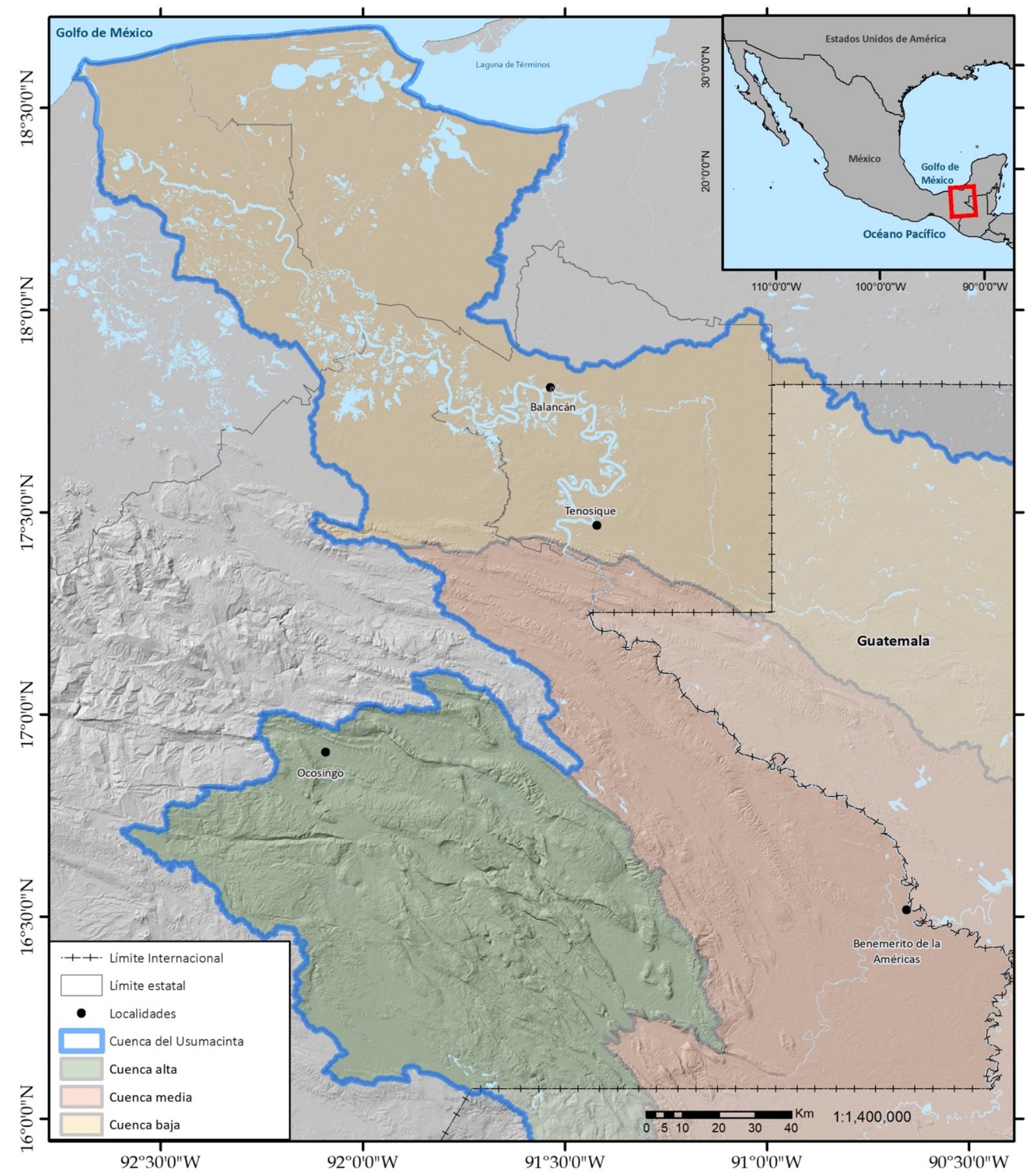

FIGURA 1. Localización geográfica de la cuenca del río Usumacinta. Se muestran las áreas ocupadas por las cuencas alta, media y baja. Sistema de coordenadas geográficas WGS84. 
tipo con la que se puede contar para esa fecha y se encuentra disponible en formato digital en el portal del Instituto. Para el Inegi (2001), las principales categorías de tipo de uso de suelo y vegetación se definieron por el aspecto dominante de la vegetación a una escala determinada (1:250 000); por ello, una categoría predominantemente herbácea no implica que existió una ausencia total de individuos arbóreos en su interior.

Debido a su escala, las categorías de esta serie tienen una mejor interpretación a escala nacional; por lo cual, algunas clases de vegetación y uso de suelo pueden considerarse como muy generales para la zona de estudio. Dentro de la CRU se encontraron presentes 46 categorías de uso de suelo y vegetación de la Serie II. De estas, se eliminaron tres categorías que no correspondían a una categoría de interés como zonas urbanas, cuerpos de agua y sin vegetación aparente. Tras esta remoción, la superficie total analizada fue menor a la que se había estimado en un principio, es decir, 3380729 ha (una diferencia de 46190.08 ha, con respecto al cálculo inicial de la CRU). De las 43 clases restantes se hizo una agrupación para facilitar la interpretación de los resultados, de acuerdo con los siguientes criterios: 1) la redundancia de categorías (las siete categorías de diferentes tipos de agricultura se agruparon dentro de la clase Agricultura); 2) se agruparon categorías de tipo de vegetación afín (las categorías de bosque de pino, encino, encino pino y pino encino formaron el grupo de bosque de pino/encino); 3) se agruparon las categorías arbóreas y arbustivas de vegetación secundaria; 4) las categorías de vegetación que tuvieran una baja representatividad en la CRU y no pudieran ser asociadas a otro tipo de vegetación se agruparon como Otras (pastizal halófilo, vegetación halófila hidrófila). De tal manera, tras realizar esta agrupación quedaron 17 categorías restantes (Tabla 1). Para fines de este trabajo a esta información se le llamará tipos de uso de suelo y vegetación.

Esta capa de tipos de uso de suelo y vegetación se tomó como la condición inicial de la superficie por categoría y a partir de esta se extrajo la superficie inicial (en el 2000) por tipo de uso de suelo y vegetación. Cabe aclarar que esta superficie inicial corresponde a la superficie de cada clase de uso de suelo y vegetación y no a la superficie de cobertura arbórea de cada clase de uso de suelo y vegetación.

\section{Información de pérdida de cobertura arbórea}

Se utilizó la actualización de 2016 de la evaluación de la pérdida de cobertura arbórea generada por Hansen et al. (2013), llamada Global Forest Change (GFC por sus siglas en inglés). Este análisis utilizó el conjunto de imágenes Landsat 5, 7 y 8 con resolución de pixel de $900 \mathrm{~m}^{2}$ (0.09 ha) disponibles para el periodo de 2000 a 2016. El estudio clasificó y cuantificó los sitios con pérdida de cobertura arbórea en función de varias medidas anuales del índice de vegetación de diferencia normalizada (NDVI por sus siglas en inglés) que incluyeron medidas estadísticas anuales como el mínimo y máximo, percentiles, bicentiles y la pendiente de la regresión de la reflectancia en función del tiempo. Este método tiene la característica de estar enfocado únicamente en detectar cambios de reemplazo de cobertura arbórea totales (de condición inicial con cobertura arbórea $>0 \%$ a una cobertura $\sim 0 \%$ de cobertura de copas) en comunidades vegetales que tuvieran una altura mayor a cinco metros. Por lo tanto, este método no permite cuantificar el disturbio que no resulte en una cobertura arbórea mayor a 0\% (Hansen et al., 2013).

Se utilizaron las capas de "lossyear" y "treecover2000" del GFC. A partir de la capa "lossyear" se hizo un mosaico de todas las pérdidas anuales para obtener una capa de pérdida total 2000-2016. Para fines de este trabajo, a esta capa se le nombró pérdida arbórea total. Por su parte, a partir de la capa “treecover2000" se obtuvo la información de porcentaje de cobertura arbórea en el 2000. Sin embargo, se consideró que todas las áreas que no tenían un valor presente en esta capa equivalían a un porcentaje de cobertura arbórea de cero. A esta capa se le llamó cobertura arbórea inicial. 


\section{Análisis de datos}

Todo el análisis de datos se realizó utilizando ArcGis 10.4. (Environmental Systems Research Institute [ESRI], 2016). Como paso inicial, se removieron de la capa de pérdida total todas las áreas que correspondían a alguna de las tres categorías de uso de suelo y vegetación previamente eliminadas (cuerpos de agua, zonas urbanas y sin vegetación aparente). A continuación, se cortó la capa de pérdida total y la de cobertura arbórea inicial por clase de uso de suelo y vegetación. De esta manera, se obtuvieron 17 capas de pérdida total y 17 de porcentaje de cobertura arbórea inicial. Por último, se enmascararon las 17 capas de cobertura arbórea inicial con las correspondientes capas de pérdida total para obtener el porcentaje de cobertura arbórea de las pérdidas (en el año 2000).

Para cuantificar las superficies ocupadas por cada clase, en el periodo inicial se hizo una consulta por atributo basándose en la información del Inegi (2001). A continuación, se utilizaron las 17 capas de cobertura arbórea inicial (una por clase) para obtener para cada tipo de uso de suelo la: 1) media y desviación estándar del porcentaje de cobertura arbórea (utilizando el intervalo completo de $0 \%$ - 100\% de cobertura arbórea) y 2) la superficie ocupada por cobertura arbórea (porcentaje de cobertura arbórea $\geq 1 \%$ ). La primera cifra tuvo el objetivo de describir la cobertura arbórea de cada clase de uso de suelo en el 2000, mientras que la última cifra se utilizó como indicadora de cuánta superficie estaba sujeta a la detección de pérdida de cobertura arbórea por el método empleado en GFC. Posteriormente, a partir de las 17 capas de pérdida total se calculó la superficie de perdida por tipo de uso de suelo y vegetación; mientras que a partir de la capa de cobertura arbórea enmascarada por la capa de pérdida total se realizó el cálculo de la media y desviación estándar (DE) de la cobertura arbórea inicial de las áreas perdidas.

Por último, los resultados de pérdida de cobertura arbórea por clase de uso de suelo y vegetación se subdividieron por cada una de las tres porciones de la cuenca (Fig. 1).

\section{ResUltadOS}

\section{Cobertura inicial en la CRU}

Las tres categorías de uso de suelo y vegetación más extensas en el periodo inicial (2000) fueron el pastizal cultivado o inducido (PCI), con 792567.20 ha (23.44\% de la superficie de la CRU), la selva alta perennifolia (SAP) con 779531.31 ha $(23.06 \%$ de la CRU) y la vegetación secundaria de SAP (VSSAP) con 385488.61 ha (11.40\%; Tabla 1). Para el PCI se encontró que casi la mitad de la superficie no presentaba una cobertura arbórea en el año 2000 y en promedio correspondió a áreas con un porcentaje de cobertura arbórea baja (33\%; Tabla 1). Por su parte, para la SAP, prácticamente la totalidad de su superficie correspondía a superficie arbolada en el año 2000, mientras que su media en porcentaje de cobertura arbórea correspondió a valores altos $(89.75 \%$ ). Por último, para la VSSAP, casi toda su superficie inicial correspondió a áreas arboladas y con porcentajes de cobertura arbórea altos también (77.28\%; Tabla 1).

\section{Condición inicial por porciones de la cuenca}

Dentro de la porción alta de la cuenca, la categoría que ocupaba la mayor superficie fue la vegetación secundaria de bosque de pino encino (VSBPE) representada en 19.37\% de esta porción de la cuenca (205 314 ha), seguida de la vegetación secundaria de selva alta perennifolia (VSSAP), con $16.70 \%$ (177 $033 \mathrm{ha}$ ) y por la selva alta perennifolia (SAP) correspondiente a 12.28\% (130 204.93 ha). Dentro de la porción media de la cuenca, la selva alta perennifolia (SAP) ocupó 66.47\% de esta porción (625 505.77 ha). Las siguientes categorías ocuparon extensiones sensiblemente menores, estas fueron: la VSSAP (17.71\%; $166643 \mathrm{ha})$ y el PCI que ocupó $16.70 \%$ de la región media de la cuenca (111 486 ha). Por último, en la porción baja de la cuenca, el PCI abarcó 43.98\% de esta porción de la cuenca (588 987 ha). Las siguientes dos categorías más extensas fueron considerablemente menores: tular (T) con 20.29\% (271 736 ha) y el manglar (M) con $7.40 \%$ de la porción baja de la cuenca (99 149 ha). 


\section{Pérdida de cobertura arbórea en la totalidad de la CRU}

En el periodo analizado (2000-2016) se perdió un total de 347318 ha de cobertura arbórea dentro de la CRU. Esta superficie equivale a $10.13 \%$ de su extensión total. Algunas de las regiones con mayor pérdida de cobertura arbórea registrada en el periodo de análisis se encontraron en la región de Marqués de Comillas, en la región sur y sureste del estado de Tabasco, en la región noreste del estado de Chiapas y en la región central de la CRU chiapaneca (Fig. 2). Se observó que algunas de las regiones con menor pérdida de cobertura arbórea correspondieron con las zonas con presencia de algún área natural protegida, por ejemplo, Montes Azules o Pantanos de Centla. Otras zonas con relativamente poca pérdida de cobertura arbórea correspondieron con áreas dominadas por alguna clase de uso de suelo de uso antrópico como Agricultura o PCI (Fig. 2).

\section{Cuantificación de la pérdida de cobertura arbórea por tipo de uso de suelo y vegetación}

El tipo de vegetación con la mayor pérdida arbórea fue la SAP con 90552 ha (Fig. 3). Esta área es equivalente a $26.07 \%$ de la pérdida total para el periodo analizado. El segundo lugar le correspondió a la vegetación secundaria arbórea de selva alta perennifolia (VSSAP) con 66499 ha $(19.15 \%)$ de la pérdida de cobertura arbórea (Tabla 1). El pastizal cultivado o inducido (PCI) fue la tercera categoría con mayor pérdida de cobertura arbórea (17.03\%) del total de la pérdida observada (59 153 ha; Fig. 3). Las primeras dos clases de uso de suelo presentaron pérdidas con alto porcentaje de cobertura arbórea $(\approx 90 \%)$. Por su parte, el PCI presentó pérdidas de áreas ligeramente menores en cuanto a su cobertura arbórea $(\approx 77.38 \%$ ). De manera opuesta, las categorías que sufrieron una menor pérdida fueron la clase de Otras con 63.57 ha, la vegetación secundaria de selva baja perennifolia espinosa subperennifolia (VSSBPES) con 88.89 ha y la sabana (S) con 1538.93 ha (Fig. 3). Todas estas pérdidas presentaron valores promedio de cobertura arbórea mayores a $60 \%$.

\section{Pérdida de cobertura arbórea por porción de la Cuenca}

En total, $9.66 \%$ de la superficie de la porción alta de la cuenca presentó pérdida de cobertura arbórea en el periodo analizado (102 477 ha). Dentro de la cuenca alta, las tres categorías que presentaron mayor pérdida en términos absolutos fueron dos categorías secundarias, es decir, VSSAP (30 725.66 ha), seguida de la VSPE (18 575 ha) y la SAP (11 551 ha; Fig. 3). Por su parte, para la porción media, $13.81 \%$ de la superficie sufrió pérdida de cobertura arbórea en el periodo de análisis, lo cual equivalió a 129964 ha. Esto indica que la cuenca media fue la más afectada por la pérdida de cobertura arbórea de las tres porciones evaluadas. En la cuenca media las tres categorías que presentaron la mayor pérdida de superficie fueron SAP (76 856 ha), VSSAP (30 044 ha) y el PCI (18 615 ha; Fig. 3). Por último, en la porción baja de la cuenca, $4.16 \%$ de la superficie sufrió pérdida de cobertura arbórea en el periodo analizado, lo cual correspondió a 55763 ha. Esto quiere decir que esta porción fue la que perdió menor cobertura arbórea de las tres evaluadas. En la cuenca baja las tres categorías que presentaron la mayor pérdida de superficie fueron el PCI (34 $114.57 \mathrm{ha}$ ), VSASAP (5 $911.74 \mathrm{ha}$ ) y el VSSMPS (5 005.15 ha; Fig. 3).

\section{DISCUSIÓN}

En la literatura se pueden encontrar dos tipos básicos de trabajos sobre la pérdida y deterioro de la vegetación: 1) los enfocados en desarrollar métodos más precisos para monitorear la pérdida de cobertura arbórea, deforestación y el cambio de uso de suelo (Carreiras, Jones, Lucas y Gabriel, 2014; Eraso, Armenteras-Pascual y Alumbreros, 2013; García y Ballester, 2016; Peralta-Rivero, TorricoAlbino, Vos, Galindo-Mendoza y Contreras-Servín, 2015; Ministerio del Ambiente Dirección General de Ordenamiento Territorial de Perú, 2014; Ometto, SousaNeto y Tejada, 2016; Sánchez-Cuervo, Aide, Clark y Etter, 2012) y 2) los enfocados en utilizar información preexistente para realizar análisis más detallados (Aguilar et al., 2016; Covaleda, Aguilar, Ranero, Marín y Paz, 2014; 


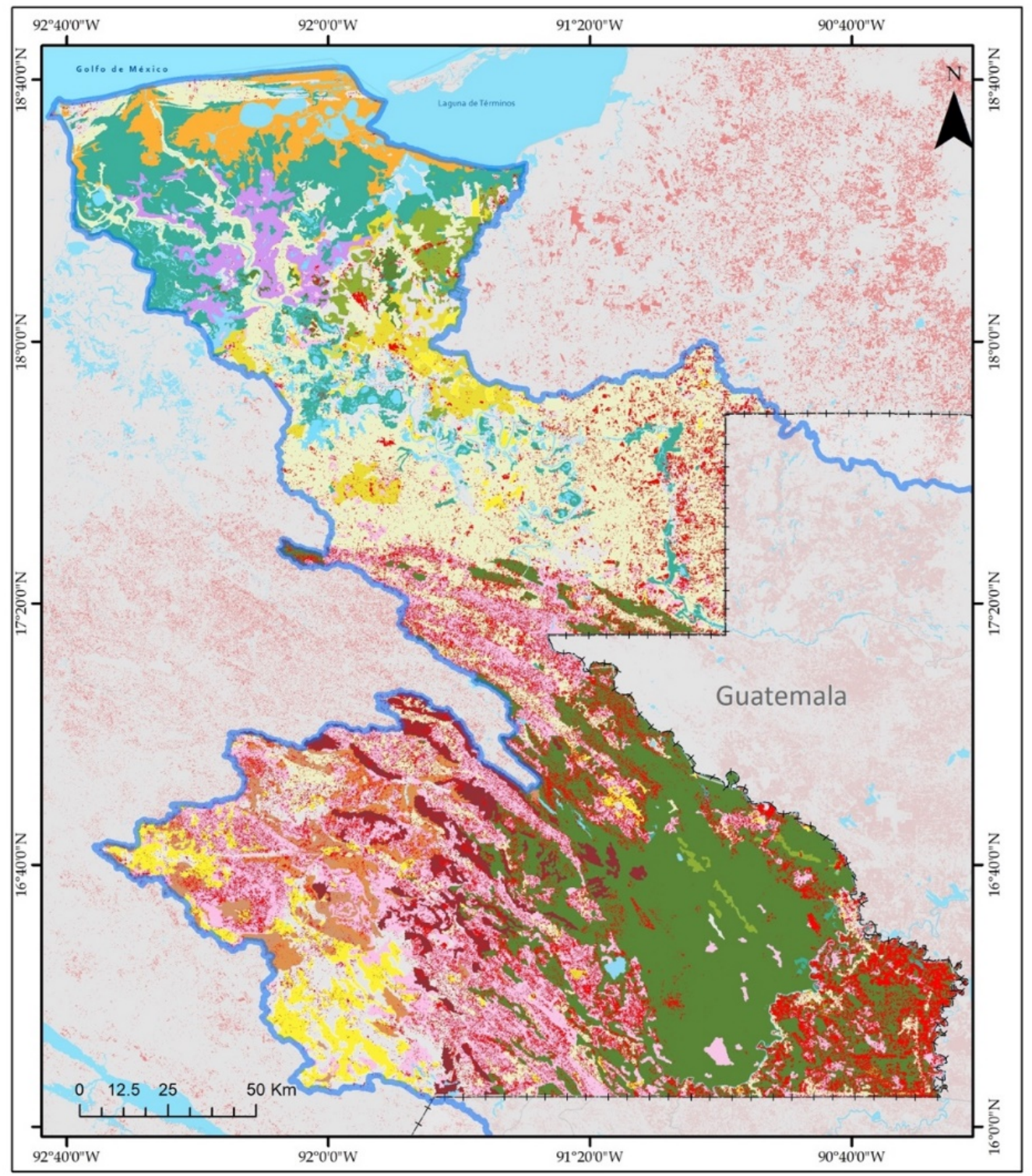

\begin{tabular}{|c|c|c|c|}
\hline Generalidades & \multicolumn{3}{|c|}{ Tipos de vegetación y uso del suelo en la cuenca del río Usumacinta } \\
\hline $\begin{array}{l}\text { Limite Nacional } \\
+\rightarrow \text { Limite Internacional }\end{array}$ & Agricultura de Temporal Anual & Manglar & Selva Alta Perennifolia \\
\hline Cuenca del Usumacinta & Bosque de Pino & Pastizal Cultivado Permanentemente & Selva Mediana Perennifolia \\
\hline Cuerpo de Agua & Bosque de Pino-Encino & Popal & Tular \\
\hline Pérdida de vegetación & Bosque Mesófilo de Montaña & Sabana & Vegetación Secundaria \\
\hline $\begin{array}{l}\text { Cobertura arbórea perdida } \\
\text { en el periodo } 2000-2016\end{array}$ & & & \\
\hline
\end{tabular}

FIGURA 2. Pérdida de cobertura arbórea (2000-2016; Hansen et al., 2013) de los principales tipos de vegetación y usos de suelo (Inegi, 2001; Serie II) en la cuenca del río Usumacinta. Sistema de coordenadas geográficas WGS84. 
Rosete-Vergés et al., 2008; Sannier, McRoberts y Fichet, 2016). Ambos enfoques son importantes y necesarios; sin embargo, la combinación de los dos tipos de trabajos es necesaria para implementar una estrategia que permita obtener información detallada y de vanguardia para tomar decisiones informadas. Dentro de estas dos categorías, el presente trabajo se encontró dentro del último enfoque.

\section{Aspectos metodológicos}

\section{Comparación de la información del GFC y la Serie II}

Un primer acercamiento del trabajo era caracterizar las clases de uso de suelo y vegetación utilizadas en términos de su cobertura arbórea. En estudios previos realizados en parte de la región de la CRU y a escala nacional, se ha documentado que es común encontrar inconsistencias

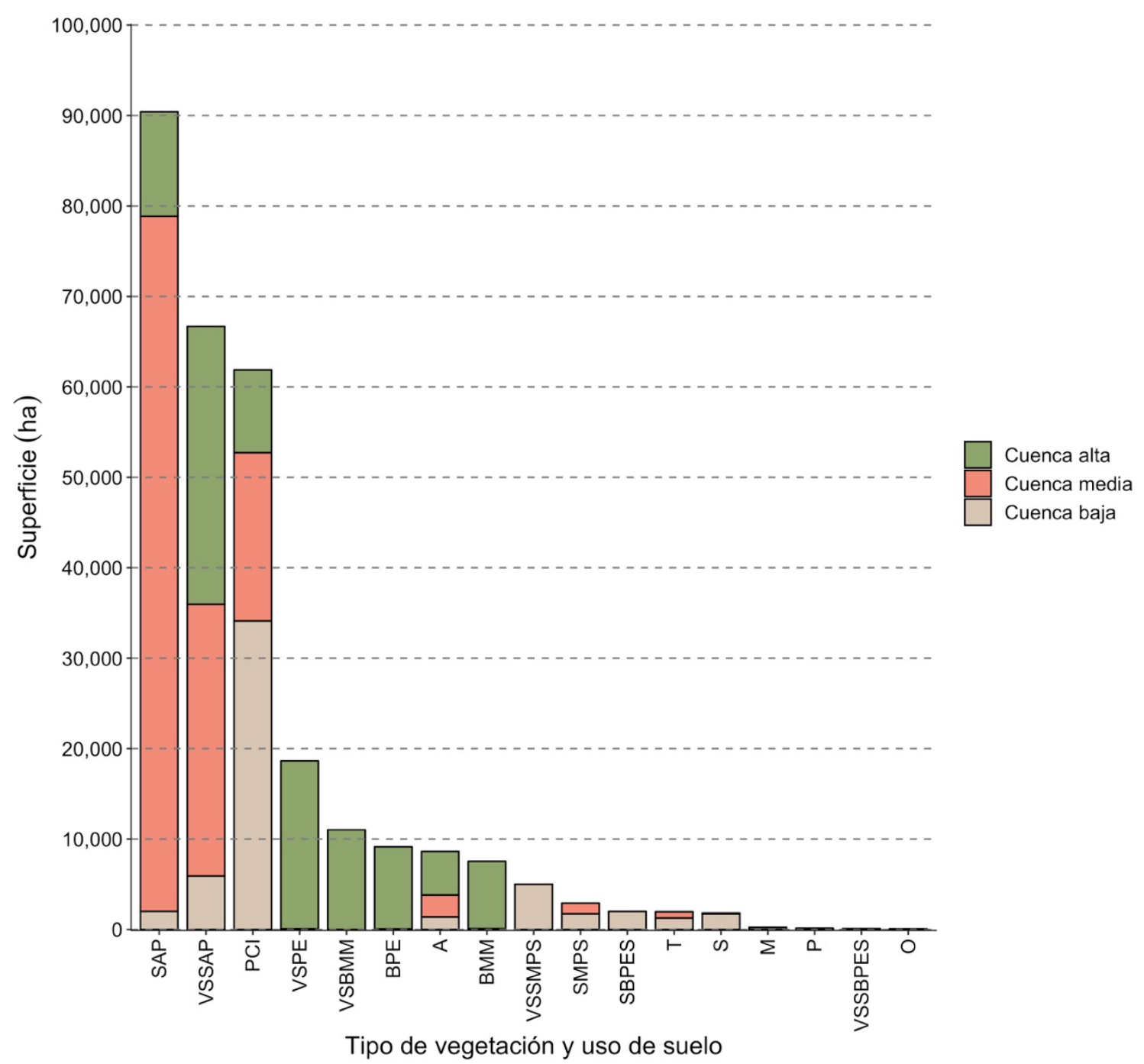

FIGURA 3. Superficie pérdida de cobertura arbórea entre 2000 y 2016 agrupada por tipo uso de suelo y vegetación de la Serie II (Inegi, 2001) y porción de la cuenca Río Usumacinta.

La gráfica muestra de izquierda a derecha las clases de uso de suelo y vegetación con mayor superficie total de pérdida de cobertura arbórea. $\mathrm{A}=$ agricultura; $\mathrm{BMM}=$ bosque mesófilo de montaña; $\mathrm{BPE}=$ bosque de pino encino; $\mathrm{M}=\mathrm{manglar} ; \mathrm{O}=$ otras; $\mathrm{PCI}=$ pastizal cultivado o inducido; $\mathrm{P}$ = popal; $\mathrm{S}$ = sabana; SAP = selva alta perennifolia; SBPES = selva baja perennifolia espinosa o subperennifolia; SMPS = selva mediana perennifolia o subperennifolia; $T$ = tular; VSBMM = vegetación secundaria de bosque mesófilo de montaña; VSBPE = Vegetación secundaria de bosque de pino encino; VSSAP = vegetación secundaria de selva alta perennifolia; VSSBPES = vegetación secundaria de selva baja perennifolia espinosa o subperennifolia; VSSMPS = vegetación secundaria de selva mediana perennifolia o subperennifolia. 
TABLA 1. Cobertura arbórea en la cuenca Usumacinta en el periodo inicial (2000), de acuerdo con el tipo de uso de suelo y vegetación.

\begin{tabular}{|c|c|c|c|c|c|c|}
\hline Clase & $\begin{array}{l}\text { Superficie } \\
\text { Inegi (ha) }\end{array}$ & $\begin{array}{c}\text { Superficie } \\
\text { arbórea ha (> 1\% } \\
\text { CobArb) }\end{array}$ & $\begin{array}{c}\text { Media y DE de \% } \\
\text { Cob arbórea }\end{array}$ & $\begin{array}{c}\text { Superficie } \\
\text { perdida (ha) }\end{array}$ & $\begin{array}{c}\text { Media y DE de \% de } \\
\text { cob arbórea de } \\
\text { pérdida }\end{array}$ & $\begin{array}{c}\text { Superficie sin \% } \\
\text { cobertura arbórea } \\
\text { perdida }\end{array}$ \\
\hline$A$ & 187602.44 & 96452.24 & $30.39 \pm 37.24$ & 8358.62 & $79.32 \pm 25.45$ & 274.44 \\
\hline BMM & 98165.30 & 97768.27 & $91.64 \pm 11.07$ & 12563.26 & $89.47 \pm 9.27$ & 5.97 \\
\hline BPE & 126166.48 & 119312.09 & $77.33 \pm 27.20$ & 9128.04 & $86.84 \pm 16.36$ & 25.14 \\
\hline M & 99148.76 & 74284.95 & $58.62 \pm 38.21$ & 12596.35 & $89.13 \pm 10.53$ & 43.95 \\
\hline $\mathrm{O}$ & 3905.25 & 3905.24 & $87.00 \pm 26.69$ & 63.57 & $75.79 \pm 33.44$ & 7.23 \\
\hline $\mathrm{PCl}$ & 792567.20 & 453921.30 & $33.65 \pm 38.05$ & 59153.02 & $77.38 \pm 26.48$ & 2758.57 \\
\hline$P$ & 55733.23 & 24902.89 & $22.11 \pm 34.33$ & 41957.15 & $92.52 \pm 7.76$ & 43.95 \\
\hline S & 64922.93 & 23643.65 & $18.06 \pm 31.43$ & 1538.93 & $60.06 \pm 35.56$ & 271.09 \\
\hline SAP & 779531.31 & 762554.64 & $89.75 \pm 18.50$ & 90552.34 & $93.47 \pm 11.25$ & 208.52 \\
\hline SBPES & 37027.08 & 26369.93 & $50.13 \pm 41.78$ & 1961.12 & $86.05 \pm 19.28$ & 28.21 \\
\hline SMPS & 55253.70 & 50476.01 & $76.31 \pm 31.94$ & 2889.59 & $85.92 \pm 20.86$ & 33.46 \\
\hline $\mathrm{T}$ & 277479.72 & 80858.78 & $15.46 \pm 30.78$ & 1733.88 & $74.72 \pm 34.17$ & 226.42 \\
\hline VSBMM & 89787.92 & 88053.74 & $83.55 \pm 19.39$ & 14925.59 & $91.51 \pm 10.41$ & 10.85 \\
\hline VSBPE & 205964.99 & 192503.45 & $73.81 \pm 28.38$ & 18589.66 & $86.76 \pm 15.70$ & 61.31 \\
\hline VSSAP & 385488.61 & 357549.62 & $77.28 \pm 30.17$ & 66498.71 & $90.19 \pm 14.69$ & 324.08 \\
\hline VSSBPES & 7693.33 & 3928.48 & $32.51 \pm 40.48$ & 88.89 & $85.93 \pm 24.07$ & 3.16 \\
\hline VSSMPS & 45791.88 & 30220.10 & $46.88 \pm 41.96$ & 4718.96 & $78.71 \pm 27.94$ & 292.70 \\
\hline
\end{tabular}

Se muestra, por tipo de uso de suelo y vegetación, la superficie abarcada en el periodo inicial (2000), la superficie con cobertura arbórea en el mismo año, así como la media y la desviación estándar (DE) del porcentaje de cobertura arbórea. Adicionalmente, se muestra la superficie que presentó pérdida de cobertura arbórea en el periodo 2000 - 2016, así como la media y desviación estándar de porcentaje de cobertura arbórea de ésta y la superficie perdida con un $\mathrm{O}$ de cobertura arbórea inicial.

$\mathrm{A}$ = agricultura; $\mathrm{BMM}=$ bosque mesófilo de montaña; $\mathrm{BPE}=$ bosque de pino encino; $\mathrm{M}=$ manglar; $\mathrm{O}=$ otras; $\mathrm{PCl}=$ pastizal cultivado o inducido; $\mathrm{P}$ = popal; $\mathrm{S}$ = sabana; SAP = selva alta perennifolia; SBPES = selva baja perennifolia espinosa o subperennifolia; SMPS = selva mediana perennifolia o subperennifolia; $T$ = tular; VSBMM = vegetación secundaria de bosque mesófilo de montaña; VSBPE = Vegetación secundaria de bosque de pino encino; VSSAP = vegetación secundaria de selva alta perennifolia; VSSBPES = vegetación secundaria de selva baja perennifolia espinosa o subperennifolia; VSSMPS = vegetación secundaria de selva mediana perennifolia o subperennifolia.

entre dos fuentes de información sobre clases de cobertura (las clases de uso de suelo y vegetación de las series del Inegi con el Inventario Forestal Nacional 2000 de la Conafor, aunque suelen mostrar buenos valores de concordancia (Mas et al., 2004; Couturier y Mas, 2009; Mas,Velázquez y Couturier, 2009).
En este sentido, resultó importante analizar la concordancia entre las fuentes utilizadas, comprobando que las categorías dominadas por elementos arbóreos (BMM, SAP, BPE, SMPS; Inegi, 2005) presentaron valores elevados de porcentajes de cobertura arbórea (75\%-92\%). Por el contrario, las categorías evidentemente dominadas por elementos no arbóreos (A, P, S, T, PCI; Inegi, 2005), 
mostraron una buena concordancia entre los dos tipos de información, con valores relativamente bajos de porcentaje de cobertura arbórea (15\%-30\%). Para los tipos de vegetación secundaria, se encontró que en general correspondían a áreas con valores de intermedios a altos en cuanto a su cobertura arbórea (32\%-84\%). Por último, hubo dos clases, M y SBPES, para las cuales los resultados de cobertura arbórea inicial fueron sorpresivos, ya que presentaron valores de porcentaje de cobertura arbórea entre 50\% y 59\%. Ambos tipos de vegetación se encuentran bajo un régimen de inundación estacional asociado a cuerpos de agua y cercano a comunidades herbáceas (INE y Semarnap, 2000b; Guerra-Martínez y Ochoa-Gaona, 2005; Challenger y Soberón, 2008; Inegi, 2017). Sin embargo, la literatura los clasifica como comunidades vegetales densas con alturas mayores a $5 \mathrm{~m}$, por lo cual se habría esperado un porcentaje de cobertura arbórea mayor (Challenger y Soberón, 2008; Inegi, 2017). Una posible futura revisión podría enfocarse en aclarar si esto se trata de una incapacidad de detección de la cobertura arbórea del GFC o una errónea designación de clase por parte de la Serie II del Inegi.

En términos generales, se encontró una buena concordancia entre la mayoría de los porcentajes de cobertura arbórea de cada clase de uso de suelo y vegetación. La variación de la concordancia entre las dos fuentes de información utilizadas en este estudio pudo deberse a: 1) la diferencia en la escala de las dos fuentes de información utilizada y 2) el enfoque de cada fuente de información. En el primer caso, la diferencia de escalas permitiría explicar parte de esas inconsistencias, ya que el área mínima cartografiable de la información de tipos de uso de suelo y vegetación correspondió a 1111 pixeles de la información de pérdida de cobertura arbórea (100 ha; Mas y Fernández, 2003; Couturier y Mas, 2009). En el segundo caso, debido a que cada fuente de información se generó con un propósito distinto, no se esperaba una concordancia exacta. Por ejemplo, la Serie II del Inegi brinda información sobre la vegetación dominante y algunas especies frecuentes (Inegi, 2017), mientras que la información del GFC brinda información cuantitativa de porcentajes de cobertura arbórea y de su pérdida.

\section{Consideraciones generales sobre los resultados}

El término de pérdida de cobertura arbórea fue elegido a propósito y no debe interpretarse como un sinónimo de deforestación. A pesar de que algunos sitios con alta pérdida de cobertura arbórea correspondan a sitios deforestados, no en todos los casos esto será así. Esto se debe a que la cuantificación de Hansen et al. (2013) incluye pérdidas que en un sentido estricto no pueden ser considerados como deforestación o pérdida de áreas boscosas. Algunas definiciones de bosque incluyen criterios tales como áreas con más de 10\% de cobertura arbórea y 2 $\mathrm{m}$ de altura (FAO, 2018b) o criterios de área mínima (70\%, 1 ha; Sannier et al., 2016). Además, la definición de un bosque puede variar entre tipos de vegetación (Aguilar et al., 2016; Sannier et al., 2016; Inegi, 2017). Por ello, resulta de suma importancia diferenciar y definir los términos de bosque, deforestación y pérdida de cobertura arbórea para poder interpretar correctamente los resultados (Brown y Zarin, 2013; Ministerio del Ambiente Dirección General de Ordenamiento Territorial de Perú, 2014; FAO, 2018b). La información de GFC al utilizar un criterio de altura del dosel mayor a $5 \mathrm{~m}$ y cobertura arbórea $\geq 1$ puede incluir o dejar fuera algunas áreas de interés. Por ello, varios trabajos previos han llamado a interpretar este tipo de información con cautela (Bovolo y Donoghue, 2017; Milodowski, Mitchard y Williams 2017; Aguilar et al., 2016).

Debido a su naturaleza no arbórea, el presente estudio no puede considerarse como una cuantificación formal de la degradación de algunas categorías dominadas por herbáceas como el tular, popal o sabana (Inegi, 2017). En su mayoría, estas clases se encontraban cubiertas por regiones arboladas en menos de la mitad de su superficie (Tabla 1). Por lo tanto, utilizando el método de GFC, resulta imposible detectar la degradación de áreas en donde existe una ausencia completa de individuos arbóreos. Para cuantificar la degradación o incluso el cambio de uso de 
suelo de estos tipos de vegetación sería necesario otro tipo de análisis (Díaz-Gallegos, Mas y Velázquez-Montes, 2008).

Debido a la naturaleza global de la cuantificación de Hansen, no es sorprendente que al analizar los datos de manera local a escala fina puedan detectarse algunos errores o imprecisiones (Aguilar et al., 2016; Sannier et al., 2016; Milodowski et al., 2017). Dichas imprecisiones pudieron ser detectadas en nuestro estudio, donde algunas de las áreas identificadas con pérdida de cobertura arbórea correspondieron a zonas cubiertas por agua, o a áreas en donde se reconoce un patrón claro del "gap fill" de imágenes Landsat 7. En este estudio, al remover del análisis las áreas que correspondieron a cuerpos de agua (Inegi, 2001), se eliminaron las áreas que se detectaron como pérdida de cobertura arbórea debido a un cambio en las condiciones hídricas y no por cambios en la cobertura arbórea como tal. Por ello, se consideró que la cuantificación de pérdida de cobertura arbórea es un estimado más realista para la zona.

Se ha documentado que al hacer comparación entre fuentes de información espacial con distinta escala y una medida de confiabilidad asociada, la confiabilidad del producto será igual a la confiabilidad de las dos fuentes multiplicadas (Couturier y Mas, 2009). Sin embargo, para el caso de las series del Inegi no cuentan con una confiabilidad explícita para sus productos, aunque trabajos previos ubican su precisión a escala nacional entre 0.74 y 0.89 (Mas, Velázquez y Couturier, 2009). En el caso de la información de GFC se señala una confiabilidad de $83.1 \%$ para la pérdida de cobertura arbórea y $99.8 \%$ para permanencia en las clases arbórea y no arbórea en bosques tropicales (confiabilidad total 99.5\%; Hansen et al., 2013); sin embargo, se ha encontrado que esta información puede contener mayor grado de incertidumbre en evaluaciones regionales o locales (Sannier et al., 2016; Milodowski, 2017; Potapov et al., 2014). Por lo tanto, en una estimación laxa, la confiabilidad de la evaluación aquí realizada debería encontrarse alrededor de $80 \%$.

Un resultado difícil de interpretar es el de las áreas registradas que se perdieron sin tener un valor de cobertura arbórea inicial en el 2000, como fue confirmado en algunos sitios (Tabla 1). La interpretación más obvia es que las áreas no presentaban una cobertura arbórea en ese año, pero que esta aumentó y se perdió en algún momento del periodo 2000-2016. Sin embargo, al revisar el anexo metodológico de Hansen et al. (2013), no se mencionan áreas que hubieran presentado esta característica. No obstante, se ha mencionado que la información de cobertura arbórea inicial puede estar sobreestimada debido a que proviene de información del sensor Modis (pixel $=500 \mathrm{~m}$ ) reescalada a la resolución de Landsat (pixel $=30 \mathrm{~m}$; Bovolo y Donoghue, 2017). Por ello, puede ser que las superficies que se perdieron entre 2000 y 2016 que no tenían una cobertura arbórea inicial correspondan a áreas ignoradas por el reescalamiento de la información.

\section{Otros estudios basados en el GFC en otras partes del mundo}

Existen otros trabajos que se han enfocado en hacer análisis comparativos entre la información de GFC y otras fuentes. A pesar de que todos ellos se han enfocado en analizar la deforestación en lugar de la pérdida de cobertura arbórea, permiten conocer la precisión del GFC a escala local. Por ejemplo, en el estado de Chiapas, al comparar las estimaciones de deforestación basándose en las Series del Inegi (2001) y GFC, existe una diferencia entre 100000 y 200000 ha en los dos periodos estimados de cinco años y la tendencia es totalmente opuesta al utilizar una u otra fuente de información (Covaleda, Aguilar, Ranero, Marín y Paz, 2014). Otros trabajos han sugerido que, al utilizar la información de Hansen et al. 2013 para estimar deforestación en bosques tropicales, la estimación de superficie resulta mayor que la encontrada a partir de datos de inventarios forestales locales (Sannier et al., 2016), aunque también se ha observado que esta información subestima la deforestación (Milodowski et al., 2017). Por ello, se sugiere contar con datos de referencia locales que permitan conocer el grado de error del GFC en una región. 


\section{Patrones generales de pérdida de cobertura arbórea}

En estudios previos sobre cuantificaciones de la deforestación y el cambio de uso de suelo en México, se pueden observar estimaciones diferentes debido al método o a las definiciones particulares de los tipos de vegetación y uso de suelo utilizados (Inegi, 2017; FAO, 2018a, Hansen et al., 2013; Mas et al., 2009; Paz-Pellat, Marin-Sosa, Medrano-Ruedaflores, Ibarra-Hernández y PascualRamírez, 2010). En el caso de México, se han realizado diversas estimaciones de cambio de uso de suelo a partir de las Series de Uso de suelo y vegetación del Inegi (SánchezColón, Flores-Martínez, Cruz-Leyva y Velázquez, 2009; Semarnat, 2016), en conjunto con información del inventario forestal nacional (Rosete-Vergés et al., 2014; Mas et al., 2009; Velázquez et al., 2002; Mas et al., 2002) y otras capas de cobertura forestal (Paz Pellat et al., 2010; Covaleda et al., 2014). A pesar de que la mayoría de estos estudios se han enfocado en cuantificar el cambio de uso de suelo, algunas de las transiciones entre clases de uso de suelo y vegetación pueden interpretarse como una pérdida importante de cobertura arbórea e incluso, deforestación; por ejemplo, la transición de la SAP a PCI. Sin embargo, esta serie de estudios difieren con el presente trabajo en dos aspectos esenciales: 1) este estudio no tiene un enfoque de cambio de uso de suelo y en su lugar, se basa en el análisis de la pérdida del componente arbóreo de la vegetación (independientemente si se trata de una clase de uso de suelo y vegetación predominantemente arbórea o no); 2) por esta razón, a diferencia de los estudios mencionados previamente, las tasas de cambio no pueden ser positivas, ya que no se está incorporando información de transición entre categorías de uso de suelo y vegetación y 3) el análisis de la pérdida de cobertura arbórea tiene una escala más fina (GFC tiene una resolución aproximada de $30 \mathrm{~m}$ de pixel) y corresponde a un periodo más actual (2000-2016). Teniendo en cuenta estas diferencias, se pueden mencionar algunos hallazgos previamente encontrados para poner en contexto nuestros resultados.

Los resultados muestran que la pérdida de cobertura arbórea en una de las cuencas más importantes del país ha tenido magnitudes preocupantes, con una pérdida de cobertura arbórea de casi $10 \%$ en la superficie de algún tipo de cobertura arbórea en los últimos 16 años. Este hallazgo sugiere que la cuenca del Usumacinta se encuentra entre las cuencas del país con mayores tasas de pérdida de vegetación natural (estimación para las cuencas del Grijalva y Usumacinta; Cuevas, Garrido, Pérez-Damián y Iura-González, 2010).

La SAP y la VSSAP fueron los tipos de vegetación con mayor pérdida en el período analizado $(26 \%$ y $19 \%$ de la pérdida de cobertura arbórea detectada, respectivamente). En estudios previos en la región, las clases de SAP y VSSAP fueron las clases con mayores tasas de conversión a pastizales inducidos y cultivados entre 1993 y 2007 (DíazGallegos et al., 2008; Ramírez-Mejía, Cuevas y Mendoza, 2011). Este patrón también es observable a escala nacional, donde las selvas han sido documentadas como uno de los primeros tres tipos de vegetación natural con mayor tasa de pérdida (Rosete-Vergés et al., 2014; Mas et al., 2009). Cabe destacar que, casi toda la superficie de cobertura arbórea perdida de SAP (SAP y VSSAP) correspondió a porcentajes de cobertura arbórea muy altos (entre 90\% y 93\% de cobertura arbórea), lo cual implica una pérdida de altos valores de biomasa (Hunter et al., 2013). Entre las dos categorías de SAP, casi se suma la mitad de la pérdida arbórea detectada en la CRU, lo cual representa muy claramente la enorme presión que tiene este tipo de vegetación.

Por su parte, el PCI fue la tercera clase de uso de suelo y vegetación con mayor pérdida arbórea, a pesar de que se trataba de una clase dominada por herbáceas (Inegi, 2017), además, casi la mitad de su superficie no contaba con una cobertura arbórea en el 2000 y en general presentaba valores bajos de cobertura arbórea (Tabla 1). Este resultado puede llamar la atención ya que normalmente estas áreas junto con otras coberturas antrópicas, en estudios de cambio de uso de suelo, se muestran con tasas positivas (clases que crecen a costa de la deforestación; Semarnat, 2016; Rosete-Vergés et al., 2014; Mas et al., 2009). Sin embargo, la interpretación de nuestros resultados es que los 
remanentes de vegetación arbórea (probablemente SAP o SMPS) en los pastizales cultivados fueron severamente fragmentados o incluso deforestados por completo en el periodo analizado (Aguilar et al., 2000; Broadbent, Asner, Keller, Knapp, Oliveira-Paulo y Silva, 2008). Este es un aspecto que queda totalmente omitido en estudios de cambio de uso de suelo, ya que la clase puede seguir siendo la misma pero presentar una fuerte pérdida del componente arbóreo. Adicionalmente, al prestar atención en los porcentajes de cobertura arbórea de las áreas perdidas, se observa que en general corresponden a sitios con un alto porcentaje de cobertura arbórea (77\%). Esta disminución podría tener graves consecuencias para la fauna de la región (Aguilar et al., 2000), además de que resulta un obstáculo para cualquier proceso de sucesión natural (Rosete-Vergés et al., 2014).

Por región de la cuenca, la porción que sufrió la mayor pérdida de cobertura arbórea correspondió a la parte media, seguida de la porción alta y por último la baja. Esto correspondió exactamente al patrón de cobertura arbórea inicial de las tres porciones de las cuencas, ya que la porción media presentó la mayor cobertura arbórea inicial, seguida de la parte alta y la baja. En cuanto a la localización por fracción de la cuenca de los tipos de uso de suelo y vegetación con la mayor pérdida arbórea se encontraron los siguientes patrones. La parte media fue la porción de la cuenca donde se concentró casi $85 \%$ de la pérdida de la SAP (76 860 ha de 90552 ha), la clase que sufrió la mayor pérdida de cobertura arbórea en la CRU. Por su parte, el restante de SAP se perdió en su mayoría en la parte alta de la cuenca (11 031. ha de 90552 ha). Para la segunda categoría de mayor pérdida arbórea en la CRU la VSSAP también presentó casi $50 \%$ de su pérdida en esta porción media de la cuenca (30 044 de 66498 ha) y casi la otra mitad se perdió en la cuenca alta (30 726 ha), donde también se observó el uso de suelo con mayor pérdida en esta porción. Por último, la tercera clase de mayor pérdida de la CRU se perdió en su mayoría en la porción baja (34 114 ha de 59 $153 \mathrm{ha}$ ), seguida de la porción media (18 $614.62 \mathrm{ha}$ ).
Al comparar los resultados de esta investigación con las más recientes tasas de deforestación calculadas para el país (Rosete-Vergés et al., 2014; Semarnat, 2016) contrasta el hecho de que la tasa de deforestación ha sido más lenta en 1976-2000 (Mas et al., 2009) y 1976-2007 (RoseteVergés et al., 2014). A pesar de que el GFC no logra abarcar un periodo tan largo como los trabajos previos, sus datos indican que la tasa de deforestación va en aumento de 2000-2016 en la CRU (Hansen et al., 2013). Además, tanto Semarnat (2016), como FAO (2018a) exponen que en el país la deforestación continúa. En este sentido, valdría la pena realizar análisis futuros a detalle para conocer el motivo de estas discrepancias en cuanto a las tendencias actuales de deforestación y pérdida de cobertura arbórea.

Por último, se considera que este tipo de revisión puede constituir el punto de partida de análisis subsecuentes, como puede ser el asociar la pérdida de cobertura arbórea de ciertos tipos de vegetación con sus causas (Angelsen y Kaimowitz, 1999; Armenteras y Rodríguez-Eraso, 2014). Adicionalmente, este tipo de acercamientos pueden resultar de gran utilidad para otras investigaciones que busquen relacionar la pérdida de la cobertura arbórea con los impactos generados por otras características de índole social, normativo, entre otros (Geist y Lambin, 2001).

\section{CONCLUSIONES}

A partir de este estudio se pueden enlistar dos patrones sobre la pérdida de cobertura arbórea en la CRU: 1) $62 \%$ de las pérdidas correspondieron a tres categorías: la selva alta perennifolia (SAP, 26\%), la vegetación secundaria de selva alta perennifolia (VSSAP, 19.1\%) y el pastizal cultivado inducido (PCI, 17.0\%). Las pérdidas de la SAP y de la VSSAP se concentraron principalmente en la porción media y media/alta de la cuenca, respectivamente; mientras que la del PCI en la parte baja. 2) Por el contrario, las áreas más conservadas en términos relativos correspondieron a áreas con baja representatividad en la CRU o clases asociadas a cuerpos de agua como el manglar o el tular. 


\section{RECONOCIMIENTOS}

Este proyecto recibió financiamiento del Consejo Nacional de Ciencia y Tecnología (Fordecyt-273646) y de la Universidad Iberoamericana (Dirección de InvestigaciónFondo S.N.I. 100).

\section{REFERENCIAS}

Aguilar, C. Martínez, E., \& Arriaga, L. (2000). Deforestación y fragmentación de ecosistemas: qué tan grave es el problema en México. Biodiversitas, 30, 7-11.

Aguilar, F. J., Nemmaoui, A., Aguilar, M. A., Chourak, M., Zarhloule, Y., \& García Lorca, A. M. (2016). A quantitative assessment of forest cover change in the moulouya river watershed (Morocco) by the integration of a subpixel-based and object-based analysis of Landsat data. Forests, 7(1), 1-19. doi: 10.3390/f7010023

Angelsen, A. \& Kaimowitz, D. (1999). Rethinking the Causes of Deforestation: Lessons from Economic Models. The World Bank Research Observer, 14, 73-98, doi: 10.1093/wbro/14.1.73

Armenteras, D., \& Rodríguez-Eraso, N. (2014). Dinámicas y causas de deforestación en bosques de Latino américa: una revisión desde 1990. Colombia Forestal, 17(2), 233-246. doi: 10.14483/udistrital.jour.colomb.for.2014.2.a07

Barnosky, A. D., Hadly, E. A., Bascompte, J., Berlow, E. L., Brown, J. H., Fortelius, M., Smith, A. (2012). Approaching a state shift in Earth's biosphere. Nature, 486, 52-58. doi: $10.1038 /$ nature11018

Bovolo, C. I. \& Donoghue, D. N. M. (2017). Has regional forest loss been underestimated? Environmental Research Letters, 12(11), 111003. doi: 10.1088/1748-9326/aa9268

Broadbent, E., Asner, G., Keller, M., Knapp, D., Oliveira-Paulo, J. C., \& Silva, J. (2008). Forest fragmentation from deforestation and selective logging in the Brazilian Amazon. Biological Conservation, 141, 1745-1757. doi: 10.1016/j.biocon.2008.04.024.

Brown, S., \& Zarin, D. (2013). What Does Zero Deforestation Mean? Science, 342, 805-807. doi: 10.1126/science.1241277

Carabias, J., de la Maza, J., \& Cadena, R. (2015). Conservación y desarrollo sustentable en la Selva Lacandona. 25 años de actividades y experiencias. México: Natura y Ecosistemas Mexicanos.

Carreiras J. M. B., Jones, J., Lucas, R. M., \& Gabriel, C. (2014). Land Use and Land Cover Change Dynamics across the Brazilian Amazon: Insights from Extensive Time-Series Analysis of Remote Sensing Data. PLoS ONE, 9, e104144. doi: $10.1371 /$ journal.pone. 0104144
Challenger, A. \& Soberón, J. (2008). Los ecosistemas terrestres. En J. Soberón, G. Halffter, \& J. Llorente-Bousquets (Comps), Capital natural de México, vol. I: Conocimiento actual de la biodiversidad (pp. 87-108). México: Comisión Nacional para el Conocimiento y Uso de la Biodiversidad.

Comisión Nacional del Agua [Conagua]. (2014). Estadísticas del Agua en México. México, Secretaría de Medio Ambiente y Recursos Naturales.

Comisión Nacional Forestal [Conafor]. (2010). Visión de México sobre REDD+. Hacia una estrategia nacional. México. Recuperado de http://www.conafor.gob.mx:8080/documentos/docs/7/1 $393 \mathrm{Visi} \% \mathrm{C} 3 \% \mathrm{~B} 3 \mathrm{n} \% 20 \mathrm{de} \% 20 \mathrm{M} \% \mathrm{C} 3 \%$ A9xico $\% 20$ sobre $\%$ 20REDD_.pdf

Cotler-Ávalos, H. (2010). Las Cuencas Hidrográficas de México: Diagnóstico y Priorización. México: Secretaría de Medio Ambiente y Recursos Naturales (Semarnat), Instituto Nacional de Ecología (INE), Fundación Gonzalo Río Arronte.

Couturier, S., Núñez, J. M., \& Kolb, M. (2012). Measuring tropical deforestation with error margins: A method for REDD monitoring in South-Eastern Mexico. En P. Sudarshana (Ed.), Tropical forests (pp. 269-296). Londres: Intech Open. doi: 10.5772/31523

Couturier, S. \& Mas, J.-F. (2009). ¿Qué tan confiable es una tasa de deforestación? ¿Cómo evaluar nuestros mapas con rigor estadístico? Investigación Ambiental, 1, 117-135.

Covaleda, S., Aguilar, S., Ranero, A., Marín, I., \& Paz, F. (2014). Diagnóstico sobre determinantes de deforestación en Chiapas. México: Alianza México para la reducción de emisiones por deforestación y degradación (Alianza México-REDD+), Agencia de los Estados Unidos para el Desarrollo Internacional (Usaid).

Cuevas, M. L., Garrido, A., Pérez-Damián, J. L., \& IuraGonzález, D. (2010). Procesos de cambio de uso de suelo y degradación de la vegetación natural. En H. Cotler Ávalos (Ed.), Las cuencas hidrográficas de México. Diagnóstico y priorización. México: Secretaría de Medio Ambiente y Recursos Naturales, Instituto de Ecología, Fundación Gónzalo Río Arronte, I. A. P. pp. 96-103.

Díaz-Gallegos, J. R., Mas, J.-F., \& Velázquez Montes, A. (2008). Monitoreo de los patrones de deforestación en el corredor biológico Mesoamericano, México. Interciencia, 33(12), 882890.

Dirzo, R. (2004). Las selvas tropicales. Epitome de la crisis de la biodiversidad. Biodiversitas, 56, 12-15. 
Eraso, N. R., Armenteras-Pascual, D., \& Alumbreros, J. R. (2013). Land use and land cover change in the Colombian Andes: dynamics and future scenarios. Journal of Land Use Science, 8(2), 154-174. doi: 10.1080/1747423X.2011.650228

Environmental Systems Research Institute [ESRI]. 2016. ArcGIS Desktop 10.4. Redlands, E.U.

Food and Agriculture Organization [FAO]. (2018a). El estado de los bosques del mundo. Las vías forestales hacia el desarrollo sostenible. Roma: FAO.

Food and Agriculture Organization [FAO]. (2018b). Global Forest Resources Assessment 2020. Terms and Definitions. Working Paper 188. Roma: FAO.

Funi, C., \& Paese, A. (2012). Spatial and temporal patterns of deforestation in Rio Cajarí Extrative Reserve, Amapá, Brazil. PLOSone, 7(12), e51893. doi: 10.1371/journal.pone.0051893

Garcia A. S., \& Ballester M. V. R. (2016). Land cover and land use changes in a Brazilian Cerrado landscape: drivers, processes, and patterns. Journal of Land Use Science, 11(5), 538-559. doi: 10.1080/1747423X.2016.1182221

Geist, H. J. \& Lambin, E. F. (2011). What drives Tropical Deforestation? A meta-analysis of proximate and underlying causes of deforestation based on subnational case study evidence. LUCC report series No. 4. Bruselas: LUCC International Project.

Gibbs, H. K., Ruesch, A. S., Achard, F., Clayton, M. K., Holmgren, P., Ramankutty, N., \& Foley, J. A. (2010). Tropical forests were the primary sources of new agricultural land in the 1980s and 1990s. Proceedings of the National Academy of Sciences, 107(38), 16732-16737.

Giam, X. (2017). Global biodiversity loss from tropical deforestation. Proceedings of the National Academy of Sciences of the United States of America, 114(23), 5775-5777. doi: $10.1073 /$ pnas. 1706264114

Guerra-Martínez, V. \& Ochoa-Gaona, S. (2005). Identificación y variación de la vegetación y uso del suelo en la reserva Pantanos de Centla, Tabasco (1990 - 2000) mediante sensores remotos y sistemas de información geográfica. $\mathrm{R} a$ Ximhai, 1, 325-346.

Hansen, M. C., Potapov, P. V., Moore, R., Turubanova, S. A., Tyukavina, A., Thau, D., \& Townshend, J. R. G. (2013). High-Resolution Global Maps of 21st-Century Forest Cover Change. Science, 342(6160), 850-853. doi: $10.1126 /$ science. 1244693

Houghton, R. A. (1990). The global effects of tropical deforestation. Environmental Science and Technology, 24(4), 414422. doi: 10.1021/es00074a001
Hunter, M. O., Keller, M., Vitoria, D., \& Morton, D. C. (2013). Tree height and tropical forest biomass estimation. Biogeosciences, 10, 8385-8399.

Instituto Nacional de Estadística y Geografía [Inegi]. (2001). Uso de suelo y vegetación a escala 1:250,000. Serie II. México: Instituto Nacional de Estadística y Geografía (Inegi).

Instituto Nacional de Estadística y Geografía [Inegi]. (2005). Guía para la Interpretación de la Cartografía. Uso del Suelo y Vegetación. Aguascalientes: Instituto Nacional de Estadística y Geografía (Inegi).

Instituto Nacional de Estadística y Geografía [Inegi]. (2017). Guía para la interpretación de cartografía. Uso del suelo y vegetación. Aguascalientes: Instituto Nacional de Estadística y Geografía (Inegi).

Instituto Nacional de Estadística y Geografía [Inegi]. (2013). Uso de suelo y vegetación a escala 1:250,000. Serie $V$. México: Instituto Nacional de Estadística y Geografía (Inegi).

Instituto Nacional de Estadística y Geografía [Inegi]. (2017). Regiones bidrográficas en formato shape a escala 1:50,000. Recuperado de http://www.Inegi.org.mx/geo/contenidos/topografia/regi ones_hidrograficas.aspx

Instituto Nacional de Estadística y Geografía [Inegi] y Secretaría de Medio Ambiente, Recursos Naturales y Pesca [Semarnap]. (1994). Programa de Manejo de la Zona de Protección de Flora y Fauna Laguna de Términos. México: Instituto Nacional de Ecología, Secretaría de Medio Ambiente, Recursos Naturales y Pesca.

Instituto Nacional de Ecología [INE] y Secretaría de Medio Ambiente, Recursos Naturales y Pesca [Semarnap]. (2000a). Programa de Manejo de la Reserva de la Biosfera Montes Azules. México: Instituto Nacional de Ecología, Secretaría de Medio Ambiente, Recursos Naturales y Pesca.

Instituto Nacional de Ecología [INE] y Secretaría de Medio Ambiente, Recursos Naturales y Pesca [Semarnap]. (2000b). Programa de Manejo de la Reserva de la Biosfera Pantanos de Centla: Instituto Nacional de Ecología (INE), Secretaría de Medio Ambiente, Recursos Naturales y Pesca (Semarnap).

Lahmanm, E. \& Córdova, R. (1999). Humedales de Mesoamerica. San José (Costa Rica): Unión Mundial para la Naturaleza (UICN).

Laurance, W. F. (1999). Reflections on the tropical deforestation crisis. Biological Conservation, 91, 109-117. doi: 10.1016/S0006-3207(99)00088-9

Lawrence, D. \& Vandecar, K. (2015). Effects of tropical deforestation on climate and agriculture. Nature Climate Change, 5(1), 27-36. doi: 10.1038/nclimate2430 
Liu, X., Liu, X., Skidmore, A., \& Garcia, C. (2017). Recovery of woody plant species richness in secondary forests in China: a meta-analysis. Scientific Reports, 7(1), 10614. doi: 10.1038/s41598-017-10898-7

Lowe, A. J., Boshier, D., Ward, M., Bacles, C. F. E., \& Navarro, C. (2005). Genetic resource impacts of habitat loss and degradation; reconciling empirical evidence and predicted theory for neotropical trees. Heredity, 95, 255. doi: 10.1038/sj.hdy.6800725

Malhi, Y., Gardner, T. A., Goldsmith, G. R., Silman, M. R., \& Zelazowski, P. (2014). Tropical forests in the Anthropocene. Annual Review of Environment and Resources, 39 , 125-159.

Mas, J.-F. \& Fernandez, T. (2003). Una evaluación cuantitativa de los errores en el monitoreo de los cambios de cobertura por comparación de mapas. Investigaciones Geográficas, 51, 73-87.

Mas, J. F., Velázquez, A., Díaz-Gallegos, J. R., Mayorga-Saucedo, R., Alcántara, C., Bocco, G., \& Pérez-Vega, A. (2004). Assessing land use/cover changes: A nationwide multidate spatial database for Mexico. International Journal of Applied Earth Observation and Geoinformation, 5, 249-261. doi: 10.1016/j.jag.2004.06.002

Mas, J.-F., Velázquez, A., Reyes-Díaz, J., Mayorga, R., Alcántara, C., Castro, R., \& Fernández, T. (2002). Monitoreo de los cambios de cobertura en México. Memorias Del II Seminario Latinoamericano de Geografía Física, Maracaibo, Zulia, Venezuela.

Mas, J. F., Velázquez, A., \& Couturier, S. (2009). La evaluación de los cambios de cobertura/uso del suelo en la República Mexicana. Investigación ambiental Ciencia y política pública, 1(1), 23-39.

Milodowski, D. T., Mitchard, E. T. A., \& Williams, M. (2017). Forest loss maps from regional satellite monitoring systematically underestimate deforestation in two rapidly changing parts of the Amazon. Environmental Research Letters, 12, 094003. doi: 10.1088/1748-9326/aa7e1e

Miller, J. \& Rogan, J. (2007). Using GIS and remote sensing for ecological mapping and monitoring. En V. Mesev (Ed.) Integration of GIS and Remote Sensing (pp. 233-268). Chichester: John Wiley \& Sons.

Ministerio del Ambiente Dirección General de Ordenamiento Territorial de Perú. (2014). Memoria Técnica. Cuantificación de la cobertura de bosque y cambio de bosque a no bosque de la Amazonía Peruana. Lima: Ministerio del Ambiente Dirección General de Ordenamiento Territorial.

Mukul, S. A., Herbohn, J., \& Firn, J. (2016). Tropical secondary forests regenerating after shifting cultivation in the
Philippines uplands are important carbon sinks. Scientific Reports, 6, 22483. doi: 10.1038/srep22483

Murray, J. P., Grenyer, R., Wunder, S., Raes, N., \& Jones, J. P. G. (2015). Spatial patterns of carbon, biodiversity, deforestation threat, and REDD+ projects in Indonesia. Conservation Biology, 29(5), 1434-1445. doi: 10.1111/cobi. 12500

Naidoo, R., Balmford, A., Costanza, R., Fisher, B., Green, R. E., Lehner, B., Ricketts, T. H. (2008). Global mapping of ecosystem services and conservation priorities. Proceedings of the National Academy of Sciences of the United States of America, 105(28), 9495-9500. doi: 10.1073/pnas.0707823105

Nelson, R. F., Kimes, D. S., Salas, W. A., \& Routhier, M. (2000). Secondary Forest Age and Tropical Forest Biomass Estimation Using Thematic Mapper Imagery: Single-year tropical forest age classes, a surrogate for standing biomass, cannot be reliably identified using single-date tm imagery. BioScience, 50(1), 419-431. doi: 10.1641/00063568(2000)050[0419:SFAATF]2.0.CO;2

O'Brien, K. L. (1995). Deforestation and climate change in the Selva Lacandona of Chiapas, Mexico: some preliminary results. Norsk Geografisk Tidsskrift-Norwegian Journal of Geography, 49(3), 105-122. doi: $10.1080 / 00291959508543416$

Ometto, J. P., Sousa-Neto, E. R., \& Tejada, G. (2016) Land Use, Land Cover and Land Use Change in the Brazilian Amazon (1960-2013). En L. Nagy, B. Forsberg, \& P. Artaxo (Eds.), Interactions between biosphere, atmosphere and human land use in the amazon basin (pp. 369-383). Ecological Studies (Analysis and Synthesis), vol 227. Berlin: Springer.

Ortiz-Espejel, B. \& Toledo, V. M. (1998). Tendencias en la deforestación de la selva lacandona (Chiapas, México): El caso de las cañadas. Interciencia, 23(6), 318-327.

Palacios-Prieto, J. L., Bocco, G. Velázquez, A., Mas, J. F., TakakiTakaki, F., Victoria, A., Luna-González, L., GómezRodríguez, G., López-García, J., Palma Muñoz M., Trejo, I., Peralta-Higuera, A., Prado-Molina, J., Rodríguez-Aguilar, A., Mayorga-Saucedo, R., \& González Medrano, F. (2000). Las condiciones actuales de los recursos forestales en México: resultados del inventario forestal nacional 2000. Investigaciones Geográficas, 43, 183-203.

Paz-Pellat, F., Marin-Sosa, M. I., Medrano-Ruedaflores, E. R., Ibarra-Hernández, F., \& Pascual-Ramírez, F. (2010). Elaboración de mapas multi-temporales de bosque, a partir de imágenes Landsat TM y ETM+ y análisis de la degradación forestal $y$ deforestación en Chiapas. Colegio de Postgraduados, El Colegio de la Frontera Sur, Conservación Internacional, UK in Mexico Foreign \& Commonwealth Office, Secretaria de 
Medio Ambiente y Vivienda del Gobierno del Estado de Chiapas.

Peralta-Rivero, C., Torrico-Albino, J. C., Vos, V. A., GalindoMendoza, M. G., \& Contreras-Servín, C. (2015). Tasas de cambios de coberturas de suelo y deforestación (1986-2011) en el municipio de Riberalta, Amazonía boliviana. Ecología en Bolivia, 50(2), 91-114.

Poorter, L., Bongers, F., Aide, T. M., Zambrano, A. M. A., Balvanera, P., Becknell, J. M., \& Rozendaal, D. M. A. (2016). Biomass resilience of Neotropical secondary forests. Nature, 530, 211-214. doi: 10.1038/nature16512

Potapov, P. V., Dempewolf, J., Talero, Y., Hansen, M. C., Stehman, S. V., Vargas, C. y Zutta, B. R. (2014). National satellite-based humid tropical forest change assessment in Peru in support of REDD+ implementation. Environmental Research Letters, 9, 124012. http://doi.org/10.1088/17489326/9/12/124012.

Quesada, M., Sanchez-Azofeifa, G. A., Alvarez-Añorve, M., Stoner, K. E., Avila-Cabadilla, L., Calvo-Alvarado, J., \& Sanchez-Montoya, G. (2009). Succession and management of tropical dry forests in the Americas: Review and new perspectives. Forest Ecology and Management, 258(6), 10141024. doi: 10.1016/j.foreco.2009.06.023

Ramírez-Mejía, D., Cuevas, G., \& Mendoza, E. (2011). Escenarios de cambio de cobertura y uso de suelo en el Corredor Biológico Mesoamericano - México. En J.-F. Mas, G. Cuevas, \& R. García (Comps), XIX reunión SELPERMéxico. México: UNAM

Rosa, I. M. D., Smith, M. J., Wearn, O. R., Purves, D., \& Ewers, R. M. (2016). The Environmental Legacy of Modern Tropical Deforestation. Current Biology, 26, 2161-2166. doi: 10.1016/j.cub.2016.06.013

Rosete-Vergés, F. A., Pérez Damián, J. L., \& Bocco, G. (2008). Cambio de uso del suelo y vegetación en la Península de Baja California, México. Investigaciones geográficas, 67, 39-58.

Rosete-Vergés, F. A., Pérez-Damián, J. L., Villalobos-Delgado, M., Navarro-Salas, E. N., Salinas-Chávez, E., \& RemondNoa, R. (2014). El avance de la deforestación en México 1976-2007. Madera y Bosques, 20(1), 21-35. doi: 10.21829/myb.2014.201173

Sánchez-Colón, S., Flores-Martínez, A., Cruz-Leyva, I.A., \& Velázquez, A. (2009). Estado y transformación de los ecosistemas terrestres por causas humanas. En R. Dirzo, R. González, \& I. J. March (Comps.), Capital natural de México, vol. II: Estado de conservación y tendencias de cambio (pp. 75-129). México: Comisión Nacional para el Conocimiento y Uso de la Biodiversidad.
Sánchez-Cuervo, A. M., Aide, T. M., Clark, M. L., \& Etter, A. (2012) Land Cover Change in Colombia: Surprising Forest Recovery Trends between 2001 and 2010. PLOS ONE, 7, e43943. doi: 10.1371/journal.pone.0043943

Sannier, C., McRoberts, R. E., \& Fichet, L.-V. (2016). Suitability of Global Forest Change data to report forest cover estimates at national level in Gabon. Remote Sensing of Environment Journal, 173, 326-338. doi: $10.1016 /$ j.rse.2015.10.032

Secretaría de Medio Ambiente y Recursos Naturales [Semarnat] y Comisión Nacional de Áreas Naturales Protegidas [Conanp]. (2016). Prontuario estadístico y geográfico de las áreas naturales protegidas de México. México: Secretaría de Medio Ambiente y Recursos Naturales, Comisión Nacional de Áreas Naturales Protegidas.

Secretaría de Medio Ambiente y Recursos Naturales [Semarnat]. (2016). Informe de la situación del medio ambiente en México. Compendio de estadísticas ambientales, indicadores clave $y$ de desempeño ambiental. Edición 2015. México: Secretaría de Medio Ambiente y Recursos Naturales.

Sexton, J. O., Song, X. P., Feng, M., Noojipady, P., Anand, A., Huang, C., \& Townshend, J. R. (2013). Global, 30-m resolution continuous fields of tree cover: Landsat-based rescaling of MODIS vegetation continuous fields with lidarbased estimates of error. International Journal of Digital Earth, 6(5), 427-448. doi: 10.1080/17538947.2013.786146

Song, C., Gray, J. M., \& Gao, F. (2011). Remote Sensing of Vegetation with Landsat Imagery. En Q. Weng (Ed.), Advances in environmental remote sensing: sensors, algorithms, and applications (pp. 3-29). Boca Raton: CRC Press Inc.

Stas, S. M. (2014). Above-ground biomass and carbon stocks in a secondary forest in comparison with adjacent primary forest on limestone in Seram, the Moluccas, Indonesia. Bogor: Center for International Forestry Research.

Steffen, W., Sanderson, R. A., Tyson, P. D., Jäger, J., Matson, P. A., Moore III, B., \& Wasson, R. J. (2004). Global change and the earth system: a planet under pressure. Berlin: Springer.

Steininger, M. K. (2000). Satellite estimation of tropical secondary forest above-ground biomass: Data from Brazil and Bolivia. International Journal of Remote Sensing, 21(6-7), 1139-1157. doi: 10.1080/014311600210119

Turner, I. M., Wong, Y. K., Chew, P. T., \& Ibrahim, A. B. (1997). Tree species richness in primary and old secondary tropical forest in Singapore. Biodiversity \& Conservation, 6(4), 537-543. doi: 10.1023/A:1018381111842

Velázquez, A., Mas J.-F., Díaz, J. R., Mayorga-Saucedo, R., Alcántara, P. C., Castro, R., Fernández, T., Bocco, G., 
Escurra, E., \& Palacio, J. L. (2002). Patrones y tasas de cambio de uso del suelo en México. Gaceta Ecológica, 62, 21 37.

Wang, K., Franklin, S. E., Guo, X., \& Cattet, M. (2010). Remote sensing of ecology, biodiversity and conservation: a review from the perspective of remote sensing specialists. Sensors, 10, 9647-9667. doi: 10.3390/s101109647

Xie, Y., Sha, Z., \& Yu, M. (2008). Remote sensing imagery in vegetation mapping: a review. Journal of Plant Ecology, 1(1), 923. doi: $10.1093 /$ jpe/rtm005

Zhang, H., Henderson-Sellers, A., \& Mcguffie, K. (2001). The compounding effects of tropical deforestation and greenhouse warming on climate. Climatic Change, 49(3), 309338. doi: 10.1023/A:101066242.
Manuscrito recibido el 18 de mayo de 2018

Aceptado el 1 de febrero de 2019

Publicado el 13 de noviembre 2019

Este documento se debe citar como:

Peralta-Carreta' C., Gallardo-Cruz, J. A., Solórzano, J. V., \& HernándezGómez, M. (2019). Clasificación del uso de suelo y vegetación en áreas de pérdida de cobertura arbórea (2000-2016) en la cuenca del río Usumacinta. Madera y Boques, 25(3), e2531779. doi: 10.21829/myb.2019.2531779

Madera y Bosques por Instituto de Ecología, A.C. se distribuye bajo una Licencia Creative Commons Atribución-NoComercialCompartirlgual 4.0 Internacional. 